\title{
"Los que viven por sus manos... y los otros". Una visita a la Unidad Popular a través de la nueva historia laboral
}

\begin{abstract}
"Those who live by their hands... and the others". A visit to the Popular Unity trough the New Latin American Labor History
\end{abstract}

\section{Diego VILCHES 1}

Pontificia Universidad Católica de Chile davilche@uc.cl

\section{Resumen}

Este ensayo planea sobre el periodo de la Unidad Popular a través de la revisión de las investigaciones de Heidi Tinsman (La tierra para el que la trabaja), Peter Winn (Tejedores de la revolución) y Franck Gaudichaud (Poder popular y cordones industriales). El argumento es que estas obras, que pueden ser enmarcadas dentro de lo que a fines de la década del ochenta se llamó la Nueva Historia Laboral, logran describir el proceso de politización y radicalización de los sectores populares chilenos entre 1970 y 1973. A diferencia de los primeros estudios sobre el periodo de la UP, focalizados en el sistema de partidos, los trabajos de Winn, Tinsman y Gaudichaud, al reconstruir las experiencias de campesinos y trabajadores, logran, por un lado, describir el significado utópico y concreto que la vía chilena al socialismo tuvo para ellos $\mathrm{y}$, por el otro, rescata su decisiva influencia en el desenlace del gobierno de Allende. Al reconstruir la agencia de estos sectores, y la historicidad del proceso revolucionario chileno, estos trabajos también logran superar las visiones que explican el quiebre de la democracia como el resultado de la excesiva polarización del sistema político chileno.

Palabras clave: campesinos; trabajadores; Unidad Popular; revolución; Allende.

\footnotetext{
1 Doctor (c) en Historia por la Pontificia Universidad Católica de Chile y Becario Doctorado Nacional ANID/2017 - 21170979. Agradezco los valiosos comentarios y correcciones que a este texto le hizo la Dra. Ángela Vergara.
}

"Los que viven por sus manos... y los otros". Una visita a la Unidad Popular a través de la nueva historia laboral

Sur y Tiempo. Revista de Historia de América, №3, enero-junio 2021, pp. 15-34.

ISSN 2452-574X

DOI: $10.22370 /$ syt.2021.3.2667 


\section{Abstract}

This essay revises the period of Unidad Popular through the review of the investigations from Heidi Tinsman (La tierra para el que la trabaja), Peter Winn (Tejedores de la revolución) and Franck Gaudichaud (Poder popular y cordones industriales). The proposition is that these works, that can be framed into what in late eighties was called the New Latin American Labor History, achieved to describe the process of politization and radicalization of the chilean popular sectors between 1970 and 1973. Unlike the first studies of the Popular Unity period, focused in the party system, the work from Winn, Tinsman y Gaudichaud, by reconstructing the experiences from peasant and workers, accomplishes, by one side, to describe the utopic and concrete meaning that the vía chilena al socialismo had for them, and on the other side, to rescue their decisive influence in the denouement of Allende's government. By rebuilding the agency of these sectors, and the historicity of the chilean revolutionary process, these works also manages to overcome the visions that explain the breakdown of democracy as the result of the excessive polarization of the chilean political system.

Keywords: peasant; workers; Popular Unity; revolution, Allende.

\section{Introducción}

El 4 de septiembre del año 2020 se conmemoraron los 50 años desde que Salvador Allende ganó la elección presidencial en Chile. A la cabeza de la Unidad Popular (UP), coalición que agrupaba a los principales partidos de la izquierda, el compañero presidente se propuso impulsar un programa de transformación social, política y cultural inédito en el mundo, ya que implicaba transitar hacia el socialismo en pluralismo y democracia. El alcance global de la vía chilena al socialismo (Riquelme, 2008) concitó, desde sus inicios y hasta la actualidad, una enorme atención de parte de investigadores en todo el mundo. En Poder obrero y popular en Chile, analizando la experiencia de los cordones industriales, y subrayando las semejanzas entre el programa de Allende con el de los del Frente Popular, Hugo Cancino y Cecilia Castro acusaron que la UP fue un gobierno más reformista que revolucionario (Cancino y Castro, 1981: 121-137).

Años después, en La Unidad Popular y el conflicto político en Chile, en vez de profundizar el análisis sobre los trabajadores radicalizados, Manuel Antonio Garretón y Tomás Moulian se enfocaron en estudiar la conflictiva relación política entre la UP y la oposición derechista y demócrata cristiana (1993). Efectivamente esta primera gran oleada de acercamientos desde las ciencias sociales -entre los que también destacaron los de Arturo Valenzuela en The Breakdown of Democratic Regimes, Chile 
(1978), Timothy Scully en Los partidos de centro y la evolución política chilena (1992), o los recogidos por Oscar Godoy en Cambio de régimen político (1990)-, buscaron en el sistema de partidos, y más bien en su incapacidad para canalizar las fuerzas centrífugas que se desataron desde en su interior, las claves para entender el quiebre de la democracia en Chile. De este modo, los sectores populares, uno de los principales actores de una revolución, aparecían como meras abstracciones estadísticas sin agencia para incidir en el curso del proceso.

Aunque el trabajo de los historiadores, como el de Marcelo Casals (2010), ha venido a subsanar estas deformaciones, esta aproximación aún está focalizada en el estudio del sistema político institucional. Otras propuestas historiográficas, como las de Joaquín Fermandois (2013), Luis Corvalán Márquez (2001) o Patricio Bernedo (2003), han seguido ahondando en la tesis de que la polarización del sistema político, expresada en un agudo deterioro del diálogo y las maneras republicanas, produjo la crisis terminal del arreglo democrático que caracterizó a las décadas centrales del siglo XX chileno (Moulian, 2002). Estas interpretaciones son problemáticas porque muchas veces responsabilizan a todas las fuerzas políticas, pero sobre todo a la izquierda, de haber generado la crisis de legitimidad que abrió la puerta a la cruenta intervención de las Fuerzas Armadas. Además, y justamente por culpabilizar a los grupos radicalizados, no logran sortear la trampa de evaluar un proceso revolucionario, llamado a transformar las estructuras sociales fundamentales, a partir de los estrechos márgenes de la democracia representativa. En efecto, es importante reiterar, como advirtió Andrés Coste, que una revolución se hace "por la construcción de un hombre nuevo dentro de una nueva sociedad y, por consiguiente, contra todo lo que se opone a esto; contra los grupos que monopolizan el poder económico, los privilegios sociales y el saber" (1968: 329).

Otras perspectivas diferentes, pero que también beben de la tesis de que el gobierno popular se encontró ante un callejón sin salida, son aquellas que explican el fracaso de Allende como el resultado de su incapacidad para controlar a la ultraizquierda y disciplinar a su propia coalición (Riquelme, 2007). Algo similar ocurre con las interpretaciones que, asumiendo un contexto regional de Guerra Fría, enfatizan el rol clave que jugó Estados Unidos, junto con la dictadura brasileña, en la desestabilización del proceso chileno (Harmer, 2013; Kornbluh, 2004). La mayoría de estas perspectivas, al pasar por alto el decisivo rol jugado por los sectores populares, y entramparse en explicar las causas de la derrota de la UP, no han logrado escapar a la trampa de analizar la vía chilena al socialismo en función, fundamentalmente, de su abrupto final el 11 de septiembre de 1973. A través de este ensayo, que revisita el periodo de la UP a través de La tierra para el que la trabaja de Heidi Tinsman (2009), Tejedores de la revolución de Peter Winn (2004) y Poder Popular y Cordones Industriales de Franck Gaudichaud (2004), nos interesa observar si lo que a fines de 
los ochenta se llamó la "nueva historia laboral" (Viotti da Costa, 1989; Weinstein, 1989), al reconstruir las experiencias y sueños de los sectores populares, permitió dar cuenta de toda la potencialidad transformadora y creativa que efectivamente alcanzó el proceso revolucionario chileno.

Estas investigaciones de Tinsman, Winn y Gaudichaud forman parte de una tendencia historiográfica que, además de ampliar los objetos de análisis (Rolle, 2003), ha buscado rescatar la experiencia de los actores olvidados por la primera oleada de estudios sobre la UP (Löwy, 2004: 9-10). De este modo, los sectores populares (Pinto, 2005), y específicamente los pobladores (Garcés y Leiva, 2005), los trabajadores (Gaudichaud, 2004; Thielemann, 2018), los mapuche (Mallon, 2005) y los campesinos (Avendaño, 2017) han sido crecientemente examinados por la historiografía, centrada, esta vez, en conocer lo que este decisivo periodo de la historia chilena significó para ellos. En este contexto, y al subrayar que los trabajadores y campesinos fueron sujetos históricos fundamentales para entender el curso del proceso revolucionario chileno, estas obras han colaborado en el desarrollo de una comprensión más compleja, menos "reduccionista y maniquea", del quiebre de la democracia en Chile (Gaudichaud, 2004: 13).

A través de la descripción de las expectativas y frustraciones de los trabajadores, rescatadas por Tinsman, Winn y Gaudichaud, no solo comprendemos lo que el periodo de la UP significó para ellos, sino que la vía chilena al socialismo, con sus virtudes y equivocaciones, se vuelve concreta y humana: subjetiva. No nos referimos solamente al ejercicio de comprender cómo la Historia afectó sus vidas, sino que fundamentalmente se trata de conocer cómo estos actores influyeron decisivamente en los logros y desenlaces de este proceso. Los tres estudios con que revisitaremos el período de la UP coinciden en señalar que el significado histórico del proceso revolucionario se encuentra en la conjunción de lo que Peter Winn denomina la revolución desde abajo y la revolución desde arriba. Es decir, en el encuentro, la mayoría de las veces conflictivo, entre el programa de transformaciones encabezados por el gobierno allendista y las prácticas políticas alimentadas por las expectativas, y miedos, que el programa de la UP despertó entre los distintos actores sociales del país.

Para los sectores populares, y apropiándose de los ideales revolucionarios clásicos, la vía chilena al socialismo representó una oportunidad inédita para transformar sus realidades (la explotación industrial y hacendal) y construir desde su propio trabajo una sociedad más justa, fraterna, democrática, socialista y feliz (Winn, 2004: 280-290). Bajo este discurso interpretaron el proceso encabezado por Salvador Allende $\mathrm{y}$, por lo tanto, actuaron en consecuencia, radicalizando un proyecto gradualista, que era frente populista (Cancino, 1981), para convertirlo efectivamente en uno revolucionario. Por eso es que, tras el retorno a la democracia, las campesinas 
del Valle del Aconcagua entrevistadas por Heidi Tinsman recordaban el Golpe de Estado del 11 de septiembre de 1973 como el momento en que los ricos volvieron a vencer a los pobres (Tinsman, 2009: 302).

Lo anterior no implica asumir que, esencialmente, los trabajadores sean los portadores de un proyecto político socialista o de clase. Por el contrario, estas experiencias subrayan, justamente, que la identidad de clase es un proceso histórico (Thompson, 2012). En el caso chileno esta identidad estuvo influida por el desarrollo, desde inicios del siglo XX, tanto de una experiencia común de explotación como por el trabajo ideológico de las direcciones políticas históricas del movimiento obrero. Si los trabajadores y la burguesía chilena entendieron que se encontraba en un momento crucial es porque el movimiento laboral chileno contaba con la experiencia de la construcción histórica del socialismo (Rojas, 2004: 57-114). Por eso es que en estas investigaciones las experiencias de los trabajadores se encuentran estructuradas en torno a una problemática mayor: entender desde una perspectiva histórica (crítica) el proceso revolucionario que busco conducir el gobierno de la UP.

\section{Apuntes sobre la nueva historia laboral}

Los tres trabajos que en este ensayo nos sirven como fuentes recogen los debates sobre la nueva historia laboral desarrollado por Emilia Viotti da Costa y Barbara Weinstein. En esta polémica se concluyó que para que la nueva historia laboral no se convirtiera en una mera recopilación de historias de vida y experiencias cotidianas de resistencia, no debía olvidarse la dimensión comparativa y teórica de la historiografía. Más concretamente, y para no caer "en el acatamiento de un modo fragmentado más que en un intento de explicación (Burke, 2001: 142-143), plantearon que la focalización en las experiencias de los trabajadores debía ser complementada con enfoques estructuralistas y problemas históricos más amplios como la historia del desarrollo capitalista en América Latina, los procesos de industrialización y la forma en que los estados latinoamericanos mediaban la conflictiva relación entre capital y trabajo (Viotti, 89: 3-24; Weinstein, 1989: 25-30). De ahí la relevancia de que la microhistoria de Textil Yarur sea, a la vez, un intento por "dilucidar gran parte de la historia moderna de Chile" e incluso parte de la historia del trabajo latinoamericano. En otras palabras, y si bien la lucha en Yarur "refleja una larga historia local y la confluencia de circunstancias específicas, fue emblemática de una revolución general desde abajo" (Winn, 2004: 13-212).

Efectivamente, y como cuestionaron María Soledad Zarate y Lorena Godoy, la "producción historiográfica marxista" clásica, obviando a las mujeres y a los sectores no sindicalizados, relató de manera evolucionista la trayectoria del movimiento obrero. (Zarate y Godoy, 2005: 18). Sin embargo, esta crítica no considera que este protagonismo, y esta visión dialéctica de la historia, se debía a que, para mediados de 
los sesenta, el movimiento obrero organizado era el principal actor político de la sociedad chilena, lo cual significaba que la revolución socialista era una posibilidad real. La focalización en las grandes centrales sindicales no era, como dice Jorge Rojas, una mera "limitación ideológica o incapacidad profesional" (Rojas, 2000: 64), sino que el resultado del proceso revolucionario que estaba en curso, tanto en Chile como en Latinoamérica (Nercesian, 2013). Más concretamente, los historiadores marxistas, a través de la producción de herramientas histórico-teóricas, trabajaban para lograr que el proletariado, a través de sus organizaciones de masas, desarrollara su conciencia como la dirección del proceso de transformaciones estructurales. De ahí su focalización en escribir la historia de las principales orgánicas del movimiento obrero. En este sentido, y como muestran tanto Winn como Tinsman, las mujeres participaron activamente en organizaciones sindicales y políticas. Fueron parte activa de un proceso revolucionario que consideraron podía ser un camino para su emancipación, a través de la apropiación de los medios de producción y de su plena incorporación al proceso productivo social (Luxemburg, 1906). Por ello es que la represión desatada después del 11 de septiembre fue especialmente cruel en contra de las mujeres que buscaron en la construcción del socialismo un camino para conseguir mayor libertad y autonomía (Zavala, 2005).

En este sentido, es necesario subrayar que fue justamente la búsqueda de las causas de la derrota del 11 de septiembre de 1973 lo que volvió necesario expandir los sujetos historiables -y por tanto de los enfoques para hacerlo- para entender cómo la experiencia de una revolución no fue la misma para todos los trabajadores, sino que, al contrario, el significado del socialismo fue diferente tanto para hombres y mujeres, como para obreros, campesinos y empleados. Justamente, porque las experiencias de los trabajadores no ocurren en el vacío (Williams, 2000), es que ninguna de las investigaciones acá analizadas prescinde, completamente, de los estudios de la vieja historia laboral chilena.

Al subrayar, con E. P. Thompson, que la identidad de clase es una construcción histórica y cultural (2012), la nueva historia laboral no invalida el concepto de conciencia o identidad de clase. Lo que rechaza es la creencia de que los trabajadores, por serlo, sean los portadores de un proyecto político socialista y revolucionario (Weinstein, 1989: 28; Rojas, 2000: 63). Para Tinsman, por ejemplo, es evidente la existencia del conflicto de clases durante la Reforma Agraria (e incluso, abona en la tesis de que la politización campesina es anterior, incluso, a la Reforma). Es, de hecho, bajo un telón de creciente lucha de clases en que se desarrollan las tensiones entre las identidades sexuales y de género producidas por la reforma agraria en el valle central chileno. En sus propias palabras, la violencia de los hombres hacia las mujeres es una forma "específica de las relaciones de género dentro de un contexto social marcado por las divisiones de clase" (Tinsman, 2009). Asimismo, una parte importante del 
libro de Peter Winn describe cómo una serie de experiencias, tanto al interior como afuera de Textil Yarur, estructuraron una fuerte identidad de clase en los trabajadores (Winn, 2004: 59-154). Estas memorias son imprescindibles para entender por qué entre 1959 y 1973 la identidad de clase obrera emergió en Chile con una potencia y organización política nunca antes vista, la cual no se ha vuelto a recuperar a la fecha.

Con todo, uno de los principales desafíos de la nueva historia laboral es cómo superar la inherente imprecisión metodológica del concepto de experiencia, y, sobre todo, cómo ésta se relaciona con la construcción histórica de la identidad de clase. Lo cierto, como argumenta Thompson sobre el concepto de conciencia de clase, es que la construcción de una identidad se encuentra estrechamente vinculada tanto a la subjetividad de los sujetos como en torno a elementos simbólicos (Thompson, 2012). Es decir, si la identidad de clase se construye a través de la experiencia del trabajo, que emerge histórica y culturalmente, el desafío es cómo los historiadores pueden acceder a esta experiencia. Particularmente, para la historia del siglo XX, lo han hecho a través de las fuentes orales (Viotti, 1989: 8-9; Winn, 2004: 23). En nuestro caso específico, la historia oral permitió captar las representaciones sociales de los trabajadores, y de esa forma, al acceder al contenido utópico del proceso revolucionario, conocer la importancia que tiene la "subjetividad militante sobre la realidad misma" (Gaudichaud, 2004: 57).

Asumiendo que la oralidad, al ser una ventana parcial al pasado, no constituye un hecho empírico, Tinsman se propuso usar la memoria de las campesinas para contrastar tanto la documentación escrita como los recuerdos masculinos acerca de la Reforma Agraria. Es así que las "historias orales" le permiten "leer en contra de las fuentes escritas", clarificando la experiencia femenina y sugiriendo significados alternativos para la Reforma (2009: 23-25). Lo anterior, implica complementar la historia desde abajo, la que es recogida a través de la oralidad, con la historia desde arriba. Por eso, en Tejedores de la revolución, Peter Winn integra un estudio macrohistórico con perspectivas históricas nacionales y fuentes escritas. Es a través de la oralidad, entonces, que estos autores recogieron los "fragmentos de una memoria dispersa" (2004: 23-25), la que, en su conjunto, refleja la histórica experiencia de clase que poseían los trabajadores chilenos que creyeron, con razón, ser los actores principales de la historia de Chile entre 1970 y 1973.

Con todo, y aunque estos autores compartan ciertos enfoques teóricos y epistemológicos, sus intenciones y motivaciones son diferentes. Mientras a Peter Winn y Franck Gaudichaud les interesa observar cómo el conflicto no resuelto entre una revolución desde abajo y una desde arriba determinó el "dramático" desenlace de la vía chilena al socialismo, a Heidi Tinsman le preocupa conocer cómo una política macro, la Reforma Agraria, alteró las relaciones de poder al interior del hogar rural chileno, y, por lo tanto, afectó decisiva y distintivamente la vida de campesinos y 
campesinas. De esa forma, al establecer una relación dialéctica entre una política estatal y su contenido y significado, a nivel local y cotidiano, Tinsman muestra que los hombres y mujeres rurales fueron afectados al mismo tiempo que radicalizaron la Reforma Agraria de la UP.

En este sentido, el aporte de Tinsman no es solamente exponer que la Reforma Agraria de la UP benefició más a los hombres que a las mujeres -al institucionalizar y enfatizar aún más los tradicionales roles de madre y esposa-, sino que su contribución es develar la vinculación entre la sexualidad y el modo en que la política adquiere una perspectiva de género $\mathrm{y}$, de ese modo, se perpetúa una sociedad estructurada patriarcalmente. Esto no significó que las mujeres no se hayan beneficiado de la Reforma Agraria ni, tampoco, que se hayan marginado de ella. Por el contrario, al postular el patriarcado como una construcción hegemónica, sostenido y reactualizado por una "multiplicidad de arreglos" históricamente negociados (Rosemblatt, 1995: 188-222; Klubock, 1995: 223-256), Tinsman sostiene que el despliegue de la Reforma les permitió a las mujeres mayores grados de autonomía y negociación al interior del hogar rural. En definitiva, y aunque institucionalizó el consuetudinario dominio masculino en el campo, al entregarle tierra solo a los campesinos, la Reforma Agraria produjo modificaciones en las relaciones de género relevantes para las campesinas, por eso es que la UP encontró en ellas una base de apoyo que, si bien no fue mayoritaria, sí fue muy sólida (Tinsman, 1995: 140).

Franck Gaudichaud por su parte tiene como objetivo comprender el avance experimentado por el proletariado y a la vez su fracaso revolucionario desde el materialismo histórico. Si bien el movimiento obrero era heredero de larga tradición de lucha, entre 1970 y 1973 desarrolló nuevas y autónomas formas de organización: los Cordones Industriales. Éstos cuestionaban las tradicionales jerarquías de clase e, incluso, la propiedad privada de los medios de producción. En sintonía con Peter Winn, pero desde el marxismo, argumenta que se debe superar una visión que confunde "la superestructura política de Chile de este período" -debates institucionales y conflictos ideológicos-, "con la realidad de la lucha de clases." El ejemplo chileno confirmaría que en épocas de fuertes convulsiones sociales las organizaciones políticas tradicionales se encuentran desajustadas, inclusos desfasadas, con respecto al movimiento social (Winn, 2004: 13-33). En otras palabras, la suerte de un proceso de revolución social no se puede medir sólo en función de la crisis del sistema político, sino que debe considerar, sobre todo, el grado de movilización autónoma y politización de los trabajadores, estudiantes y sectores populares. Esto marca una diferencia fundamental entre este trabajo y los de Winn y Tinsman, ya que a Gaudichaud le interesan las experiencias de los trabajadores en torno a su relación con el desarrollo del "poder popular". Hay que destacar que, si bien Peter Winn conoce los debates marxistas, su comunidad de referencia es fundamentalmente la 
historia laboral, y particularmente la nueva historia laboral. Por su parte, el acercamiento de Franck Gaudichaud a la historia laboral está determinado por su cercanía al materialismo histórico.

\section{La experiencia en el trabajo revolucionario}

Las investigaciones de Winn y Tinsman, y también de Thielemann (2018), explican por qué se produjo, y en qué consistió, la radicalización del movimiento laboral chileno de los sesenta y setenta. Esto no quiere decir que en el periodo anterior, cuando fue menos frecuente que los trabajadores entraran en conflictos abiertos con el régimen de explotación laboral, el movimiento laboral chileno careciera de conciencia de clase. En efecto, el conflicto entre capital y trabajo, producto de la relación de explotación que a través del salario posibilita que el capital se apropie de la plusvalía producida por la fuerza de trabajo, es estructural bajo el modo de producción capitalista (Luxemburg, 2015). Que esto no siempre tome la forma de una lucha frontal se explica porque muchas veces ese antagonismo se resuelve mediante una “colaboración pragmática” (Viotti, 1989: 12-13).

De hecho, tanto en la hacienda como en las industrias las relaciones entre patrón y trabajadores eran negociadas constantemente. El paternalismo autoritario que existió tanto en Textil Yarur como en las haciendas del valle central chileno fue parte de lo que Laura Baldoni engloba como "estrategias empresariales", con las que intentaban conjurar la permanente conflictividad producida por la relación entre capital y trabajo (2011). En este sentido, la estratificada cultura de la hacienda estaba conformada por una serie de ritos paternalistas que al destacar la "generosidad" patronal, tenían la función de reforzar su autoridad. Naturalmente, eso no impedía que los inquilinos y peones fueran conscientes de sufrir, en sus cuerpos, la explotación patronal. De hecho, a través de "formas de resistencia cotidianas", desafiaban la autoridad patronal y reinterpretaban su relación laboral. En este sentido es interesante destacar la polisemia asociada a la entrega de alimentos y licor. Mientras el patrón buscaba enfatizar que estos constituían regalos que, en última instancia, dependían de su buena voluntad; fue frecuente que los campesinos la entendieran como un derecho consuetudinario que les correspondía como parte de un acuerdo tácito (Tinsman, 2009: 53-61)

Asimismo, si Juan Yarur fue capaz de resolver pacíficamente varios de los conflictos laborales que sufrió se debió a que, en una medida relevante, los trabajadores se sintieron representados por el discurso de la empresa como una gran familia unida por lazos recíprocos de favor y obligación. Huelga decir que cuando el consenso no funcionó, Yarur no tuvo reparos en usar la fuerza para reprimir a los trabajadores movilizados. De hecho, en paralelo a la estrategia paternalista, Yarur poseía un férreo sistema de soplonaje y control social interno en 
Téxtil Yarur. En ese sentido, Perry Anderson tiene razón cuando plantea que, aunque el consenso es necesario para la mantención del modo de producción capitalista, este último descansa, en última instancia, en la coerción (Anderson, 1981). Al igual que en el caso del discurso "de la familia ferroviaria" argentina (Baldoni, 2011: 148151), la patronal textil logró desarrollar un mercado interno del trabajo. De esa forma, la disciplina laboral se fundó "en un contrato implícito: lealtad por trabajo seguro". Este equilibrio se quebró cuando, a inicios de los sesenta, los hijos de Yarur implementaron un sistema taylorista de producción; lo que se tradujo en un masivo despido de trabajadores. Aunque los obreros sabían que no contaban con el apoyo gubernamental, este fue uno de los momentos de mayor conflictividad laboral en Yarur, cuando se movilizaron para reivindicar un sindicato independiente (y no “apatronado"). En efecto, si en 1962 fue imprescindible luchar por un sindicato libre, fue porque Don Juan ya no estaba para proteger a los trabajadores (Winn, 2004: 6081).

La derrota sufrida por los trabajadores de Yarur en 1962 fue tanto una experiencia traumática como formativa. Por un lado, implicó la consolidación del régimen de explotación taylorista. Por otro, los convenció aún más de que para luchar por un sindicato libre era necesario contar con un apoyo gubernamental que equilibrase la asimétrica relación de poder entre capital y trabajo. Esta experiencia es vital para comprender por qué tras la elección de Allende los trabajadores de Yarur, dirigidos por trabajadores jóvenes -imbuidos de una cultural generacional rebelde y mayor identidad de clase, al ser socializados en barrios obreros- se lanzaron a la conquista, primero, de un sindicato independiente y, después, del traspaso de Textil Yarur a la nueva Área de Propiedad Social (Winn, 2004: 81-129).

La radicalización de importantes grupos de trabajadores durante la UP puede ser explicada, en términos generales, como el producto de la conjunción de "herencias históricas específicas, eventos históricos y una causalidad combinada y coyuntural" (Stillerman, 2005: 170). En otras palabras, en ese momento histórico se conjugó la "larga marcha" de los partidos políticos de izquierda con la experiencia cotidiana de explotación de los trabajadores chilenos. En ese sentido, los trabajadores radicalizados no fueron marionetas, embrujadas por un discurso revolucionario, en manos de las históricas direcciones políticas del movimiento obrero chileno (Gaudichaud, 2004: 89-365). Por el contrario, y como sugiere Tinsman, no fueron los dirigentes políticos ni sindicales los que convencieron a los campesinos de que ellos padecían el dominio de una clase, sino que, por el contrario, esto era algo que ellos sufrían cotidianamente (Tinsman, 2009: 54-256). De este modo, y al igual que lo que ocurrió con la adopción del anarquismo en el México rural a fines del siglo XIX, que representó las históricas demandas campesinas por autonomía local y redistribución de la tierra (Lida e Illades, 2001: 103-149), la 
apropiación que los trabajadores y campesinos chilenos hicieron de la vía chilena al socialismo fue, en palabras de Roger Chartier, "dependiente e inventiva" (1995: 24). De este modo, el socialismo, en tanto discurso y horizonte utópico, permitió a los trabajadores enmarcar sus trayectorias de vida, con sus conflictos, experiencias, sueños y frustraciones, dentro de un proyecto de transformación social y político que tenía una dimensión nacional, regional y mundial.

Los sectores populares entendían, como atestigua la canción de Inti Illimani, que la elección de Salvador Allende no era un mero cambio de Presidente, sino la posibilidad de que el "pueblo" construyera un Chile muy diferente (Inti Illimani, 1970). La llegada al poder del gobierno popular apareció, de este modo, como "una luz verde" para que trabajadores y campesinos avanzaran, más decididamente, hacia la socialización de los medios de producción. (Tinsman, 2009: 270-274). De hecho, los propios trabajadores recordaban que Allende le había advertido en su cara a Yarur que, de llegar a la presidencia, expropiaría la textil (Winn, 2004: 193-212). La historia de esta industria, en donde sus trabajadores pasaron de demandar un sindicato autónomo en 1962 a exigir su traspaso al Área de Propiedad Social en 1971, ilustra bastante bien el proceso de radicalización obrera y popular que experimentó Chile durante los largos años sesenta (Thielemann, 2018). Para los trabajadores que habían vivido la derrota de 1962, subvertir las relaciones de propiedad al interior de la fábrica, producir sin patrón y ser "los amos de sus propios destinos", era un sueño cumplido. Estos fueron algunos de los significados concretos que para para los obreros industriales tuvo la vía chilena al socialismo, la cual avanzaría al ritmo de su propio esfuerzo y trabajo (Winn, 2004: 193-310). Para los campesinos, por su parte, el socialismo significaba que por fin la tierra sería para quienes la trabajaban, lo que, en suma, también les permitiría convertirse en los dueños de su futuro. Para las campesinas, fue la posibilidad de exigirle a los varones, en tanto esposas y madres, una relación de mayor igualdad y compañerismo (Tinsman, 2009: 263-169).

Con esto en mente, los trabajadores emprendieron la tarea de construir "desde abajo" el socialismo, a través de una acción política radicalizada (oleada de tomas de fundos y de empresas). Este impulso terminó chocando con un proyecto de reformas estructurales, "la revolución desde arriba", que era más frente populista que revolucionario. En efecto, el gobierno de Allende se autodefinió como una etapa necesaria de colaboración de clases para acumular fuerzas o, en otras palabras, la especificidad de la vía chilena al socialismo residía en que la toma del poder no precedía, sino que era la consecuencia de la transformación social. Por eso es que mientras en el programa de gobierno eran vagas e imprecisas las referencias al "poder popular", sí eran claras sus características productivistas y economicistas (Cancino y Castro, 1981: 121-137). De esa forma, lo que Peter Winn llama la 
revolución desde arriba se encontró impregnada por una contradicción principal: se definió como el gobierno popular y pretendió representar una movilización social radicalizada, pero al mismo tiempo, hizo constantes llamados a los trabajadores a no sobrepasar las instituciones ni "las medidas previstas por su programa". De hecho, frente a la disyuntiva entre reforma y revolución, el compañero presidente se preocupó más de apaciguar los temores -poniendo a las Fuerzas Armadas como garantes de la constitucionalidad-, que de pavimentar un camino al socialismo (Gaudichaud, 2004: 21-28). De esa forma, se produjo una tensión entre ambas revoluciones que, al no resolverse, terminó siendo fatal para la suerte del gobierno popular y del proyecto de reformas estructurales que se desarrolló a su alero (Winn, 2004: 22-212).

El que menos de un cuarto de las empresas que fueron traspasadas al Área de Propiedad Social estuvieran dentro del plan original del Gobierno prueba que era la revolución de los trabajadores, con sus visiones y prioridades, la que estaba guiando el ritmo de la transición al socialismo, es decir, estaba moldeando a la revolución de arriba. Las clases propietarias y la derecha lo tenían bastante claro cuando alegaban indignados que "los rotos se estaban tomando Chile". Con todo, es cierto que la aceleración del proceso revolucionario no despertó las mismas esperanzas y sueños. Por el contrario, influyentes sectores de trabajadores, sobre todo las clases medias y algunos colegios profesionales, la percibieron con temor y ansiedad (Casals, 2019). Incluso, entre los propios trabajadores radicalizados que se comprometieron con la liberación de Textil Yarur había grupos que no habrían apoyado a Allende si hubieran pensado que los llevaría hacia una guerra civil (Winn, 2004: 303-323).

A mediados de 1972 era evidente que el Gobierno de la UP enfrentaba tanto desequilibrios económicos (Winn, 2004: 305-306) como una creciente lucha de clases y polarización política. La radicalización del proceso convenció a las clases propietarias de que era imposible llegar a un acuerdo con la UP -porque el Gobierno no se decidía a reprimir la agitación de los trabajadores-. Los Gremios patronales se unieron bajo la defensa de la propiedad privada y, manipulando la ansiedad de los pequeños comerciantes, los atrajeron hacia su bando (Casals, 2019; Power, 2008). La vía chilena al socialismo, según la interpretación de Winn, había sido lanzada, prematuramente, a la confrontación de clases. Por otro lado, las tensiones entre ambas revoluciones se agravaban por el impulso obrero de nivelar las diferencias sociales y construir una comunidad igualitaria. De ese modo, muchos empleados y profesionales, que consideraban tener una mayor dignidad que los obreros, resentían la pérdida de su estatus y privilegios. En Yarur, luego de su expropiación, fueron muchos los supervisores que entendieron el avance obrero como un ataque a su tradicional autoridad. De hecho, fue bastante común que los empleados de clase media resintieran los intentos de ser incorporados a la categoría de clase trabajadora. 
Estos grupos, confrontados a la radicalización obrera y campesina, se aferraron a su imagen de clase media y se identificaron cada vez más con la oposición demócrata cristiana (Winn, 2004: 296-299).

En el campo, la polarización en que se encontraba la sociedad chilena tuvo ribetes aún más dramáticos. La radicalización de la Reforma Agraria durante el gobierno de la UP demostró las profundas diferencias y conflictos de intereses que existían entre campesinos. Las disputas en contra de los hacendados dieron paso a luchas entre campesinos que ya habían sido beneficiados con la Reforma Agraria y los que todavía presionaban por ser incluidos en ella. Esto se agudizaba producto que, a diferencia de los asentamientos de la fase democratacristiana, el proyecto de la UP, a través de los Centros de Reforma Agraria (CERA), tenía una visión más colectiva de la propiedad de la tierra. De este modo, si durante la primera fase de la Reforma la masculinidad campesina se construía en torno a la solidaridad de clase y en oposición al patrón; durante la UP, la mitad del movimiento rural se burlaba de la mitad que se había desmovilizado, tachándolos de poco hombres y traidores a la clase. Los aludidos replicaban que los otros "eran unos matones arrogantes" que con su irresponsable acción (tomas de fundos) arriesgaban todos los logros conseguidos con su anterior movilización. De esa forma, los rumores de intentos de asesinatos entre pares marcan cómo el conflicto social se estaba dando al interior mismo del movimiento campesino (Tinsman, 2009: 280-281).

El crecimiento de la conflictividad en el campo, y entre los propios campesinos, tuvo profundas consecuencias para las mujeres. Si bien los conflictos entre campesinas eran corrientes, lo que cambió fue que estas disputas fueron concebidas como "pugnas de carácter político". Las divisiones partidistas entre las mujeres contaron con un componente de género específico, ya que las tensiones más fuertes se dieron en el contexto de la instalación de las Juntas de Abastecimiento y Control de Precios (JAP). Más que la escasez, las campesinas lamentaban que se produjeran lo que consideraban arbitrariedades político-partidistas en la distribución de los bienes de primera necesidad. Al quebrar las redes tradicionales de reciprocidad que habían permitido la sobrevivencia de la economía familiar rural, y no ofrecer otras estructuras alternativas, muchas mujeres consideraban que la "política estaba yendo demasiado lejos". Las campesinas que se volvieron escépticas de la Unidad Popular lo hicieron porque temían que el conflicto de clases borrase beneficios materiales que la Reforma Agraria había creado. Esta actitud no era "simple hostilidad" en contra de la UP, sino que más bien el resultado de su vulnerabilidad sexual y de género "al interior del proceso de lucha política". De esa forma, tanto en la ciudad como en el campo, hombres y mujeres fueron progresivamente empujados a decidir de qué lado estar (Tinsman, 2009: 282-300). 
A pesar de todo esto, del sectarismo al interior de la coalición de la Unidad Popular, de la crisis económica y de la creciente polarización en que se encontraba la sociedad chilena, la coalición gubernamental había aumentado su apoyo electoral en más de un 40\% entre la elección presidencial de septiembre de 1970 y la parlamentaria de marzo de 1973. Según Peter Winn era producto de que "revolución desde abajo se había transformado en un catalizador de la revolución desde arriba." Fue la movilización popular, los trabajos voluntarios tanto de trabajadores como estudiantes, los que hicieron frente al paro de camioneros de octubre de 1972. En este contexto, el surgimiento de los Cordones Industriales, organizaciones que agrupaban a los trabajadores provenientes de diversas industrias de un determinado territorio, y que dan cuenta de la maduración tanto del proyecto como de la identidad de clase del proletariado chileno, no solo puso en cuestión las relaciones de producción vigentes, sino que marcó una clara ruptura con las formas tradicionales de "hacer política" (Gaudichaud, 2004: 33-35). De esa manera, y si bien la lucha de los trabajadores se hacía en nombre de la defensa del gobierno popular, lo hacían sobre bases propias que desbordaron a las direcciones políticas tradicionales del movimiento obrero (Winn, 2004: 211-299).

Lo anterior implicó la crisis de la CUT y los partidos tradicionales de la izquierda, ya que fue al interior de los Cordones Industriales, y de las fábricas integradas a ellos, en donde se vivió el mayor grado de "democracia trabajadora real" en la historia chilena. Ahí fue donde el gobierno de la Unidad Popular, y el tradicional marco sindical, fue desbordado por la presión que venía desde abajo. Por el contrario, las empresas con una fuerte presencia comunista y demócrata cristiana demostraron "inercia y lentitud para hacer participar a los trabajadores en la gestión" de la industria. El problema fue que "tanto desde el punto de vista orgánico como del proyecto político" la revolución desde abajo (el principal peligro para las clases dominantes), no logró desarrollarse completamente (Gaudichaud, 2004: 3943).

De hecho, la contrarrevolución no iba a esperar que se desarrollara el "poder popular" para dar el golpe definitivo. En efecto, para 1973 los Cordones Industriales todavía se encontraban en un estado embrionario. Su capacidad de movilización se limitó a coyunturas de crisis y, de hecho, la mayor parte del tiempo, el movimiento laboral será dependiente del Estado y la iniciativa gubernamental. En Yarur esta debilidad se expresó patentemente cuando los trabajadores esperaron el "permiso de Allende" para tomarse la fábrica (Winn, 2004: 243-250). La carencia de una "dirección autónoma y preparada para asumir" las consecuencias del proceso revolucionario que encabezaba la izquierda, provoca que el "movimiento obrero se encuentre sin recursos defensivos ideológicos y político-militares” para defender su 
revolución el 11 de septiembre de 1973 (Gaudichaud, 2004: 8; Cancino y Castro, 1981).

\section{Conclusiones}

En menos de una semana el Golpe Militar que perpetraron las Fuerzas Armadas chilenas destruyó "la ilusión del poder popular". Lo que se clausuró con el éxito contrarrevolucionario fue la posibilidad de que la clase trabajadora volteara "su mundo jerárquico patas para arriba" y se convirtieran en los dueños de su destino. Se extinguía también la posibilidad de trabajar, al controlar ellos los medios de producción, en una comunidad igualitaria y libre de la explotación patronal. Cuando los militares llegaron a los campos, las campesinas se dieron cuenta que "ellos habían venido a quitarnos nuestra tierra. Nosotros sabíamos que había terminado" (Tinsman, 2009: 301). Para los trabajadores de Textil Yarur significó un recrudecimiento del antiguo régimen. La empresa ya no les iba a pertenecer, ya que sería devuelta a Amador Yarur. La experiencia de Berta Castillo, una trabajadora de Ex-Yarur, refleja muy bien lo que significó para los trabajadores la derrota de la Revolución Chilena. Con treinta años ya se veía vieja, en menos de cinco meses había perdido su trabajo, su casa y su esposo, "pero lo peor de todo es que ellos han matado mi sueño [...] era un sueño tan hermoso" (Winn, 2004: 310-331). Ese era el significado utópico, pero también concreto, que tuvo la vía chilena al socialismo. Lo que seguirá es una historia conocida. Los trabajadores pasarán, a medida que avance la Dictadura Militar, a ocupar un lugar secundario en la sociedad chilena (Rojas, 2000: 47); y la contrarrevolución neoliberal se fundará en la pauperización del trabajo urbano y rural.

La teoría del empate tiene razón al explicar que fueron tanto el discurso radicalizado de la izquierda como el de la oposición los que tuvieron un rol relevante en el quiebre de la democracia en Chile. Sin embargo, y como muestran los trabajos de la nueva historia laboral, "la revolución desde abajo" había desbordado y agotado, justamente, los mecanismos de representación del régimen presidencialista chileno. Las tomas de fundos, la socialización de las fábricas, el desarrollo de los Comandos Comunales y los Cordones Industriales reflejan que "los actores olvidados de la UP" presionaban por formas de democracia participativa popular, e incluso, socialistas. La experiencia de clase de los trabajadores chilenos había llegado a un punto de maduración tal, que era imposible subsumirla bajo las agotadas formas de la democracia representativa y presidencialista chilena.

Por esa razón es que la fuerza de la Dictadura se focalizó justamente en contra de quienes habían conformado la revolución desde abajo: trabajadores, pobladores y la estructura sindical. Peter Winn señala que "la mira e intensidad de la represión reflejó el grado y profundidad de la movilización popular en Chile. Era un homenaje 
irónico al éxito de la revolución desde abajo". Entre el 10 y el 20\% de la fuerza laboral de las industrias socializadas fue purgado y puesto en listas negras de manera que se mantuvieran, crónicamente, desempleados (Winn, 2004: 327). En efecto, la Dictadura Militar tuvo como objetivo destruir completamente toda la experiencia de clase que habían alcanzado los trabajadores hasta ese minuto. No era posible calmar la movilización popular con regalías, ya que el movimiento laboral había alcanzado un grado de madurez en el que se había dado cuenta de que podían producir sin patrón. En definitiva, podían iniciar la construcción del socialismo.

En este trabajo hemos querido destacar que es imprescindible tener en cuenta que la experiencia histórica de la izquierda chilena, que encuentra su culminación entre 1970 y 1973, no es solamente la “obra de un puñado de dirigentes, pero sí, sobre todo y ante todo, un movimiento colectivo dentro del cual participaron militantes en el anonimato". Estas experiencias son las que, hasta los trabajos de Winn, Tinsman y Gaudichaud, no habían sido lo suficientemente consideradas. Al tomarlas en cuenta podemos comprender el significado, al mismo tiempo trascendente y cotidiano, de la derrotada Revolución Chilena.

\section{Bibliografía}

Anderson, P. (1981): Las antinomias de Antonio Gramsci. Estado y revolución en Occidente. Barcelona, Fontamara.

Avendaño, O. (2017): "Reforma agraria y movilización campesina en Chile (19671973) y Perú (1969-1976)”, Polis. Revista Latinoamericana, 47, pp. 1-23.

Baldoni, L. (2011): "La familia ferroviaria a principios del siglo XX: Bienestar y lealtades de hierro en el Ferrocarril Central Argentino", en D. Dicósimo y S. Sominassi, comp., Trabajadores y empresarios en la Argentina del Siglo XX: Indagaciones desde la historia social. Rosario, Prohistoria ediciones.

Bernedo, P. (2003): "La prensa escrita durante la Unidad Popular y la destrucción del régimen democrático", en C. Rolle, 1973: La vida cotidiana de un año crucial. Santiago, Planeta.

Cancino, H. y C. Castro (1981): Poder obrero y popular en Chile. 1970, 1973: Trayectoria histórica del movimiento obrero chileno. Dinamarca, Aarhus Universitet.

Casals, M. (2010): El alba de una revolución: la izquierda y el proceso de construcción estratégica de la "vía chilena al socialismo". 1956-1970. Santiago, LOM. 
Casals, M. (2019): “The insurrection of the Middle Class: Social Mobilization and Counterrevolution during the Popular Unity Government, Chile, 1970-1973”, Journal of Social History, 110, 1-26.

Chartier, R. (1995): El mundo como representación. Barcelona, Gedisa.

Corvalán, L. (2001): Del anticapitalismo al neoliberalismo en Chile. Santiago, Sudamericana.

Coste, A. (1968): “El derecho vigente; un obstáculo para la revolución”, Mensaje, 17 (171).

Fermandois, J. (2013): La revolución inconclusa: la izquierda chilena y el gobierno de la Unidad Popular. Santiago, Centro de Estudios Públicos.

Garcés, M. y S. Leiva (2005): El Golpe en La Legua. Santiago, LOM.

Garretón, M. y T. Moulian (1993): La Unidad Popular y el conflicto político en Chile. Santiago, CESOC.

Gaudichaud, F. (2004): Poder Popular y Cordones Industriales. Testimonios sobre el movimiento popular urbano, 1970-1973. Santiago, LOM.

Godoy, O. (1990): Cambio de régimen político. Santiago, Universidad Católica.

Harmer, T. (2013): El gobierno de Allende y la guerra fría Interamericana. Santiago, Universidad Diego Portales.

Inti Illimani (1970): “Canción del poder popular”, en Canto al programa. Chile.

Klubock, T. (1995): "Hombres y mujeres en el Teniente. La construcción de género y clase en la minería chilena del cobre, 1904-1951”, en L. Godoy, ed., Disciplina y desacato. Construcción de identidad en Chile, siglos XIX y XX. Santiago, SUR, pp. 223256.

Kornbluh, P. (2004): Pinochet: los archivos secretos. Barcelona, Crítica. 
Lida, C. y C. Illades (2001): "El anarquismo europeo y sus primeras influencias en México después de la Comuna de París, 1871-1881”, Historia Mexicana, 1, pp. 103149.

Löwy, M. (2004): "Los actores olvidados de la Unidad Popular", en F. Gaudichaud, Poder Popular y cordones industriales. Testimonios sobre el movimiento popular urbano, 1970-1973. Santiago, LOM.

Luxemburg, R. (1906): Huelga de masas, partido y sindicato. Córdoba, Cuadernos Pasado y Presente.

Luxemburg, R. (2015): Introducción a la Economía Política. España, Siglo XXI.

Moulian, T. (2002): Chile actual: anatomía de un mito. Santiago, LOM.

Nercesian, I. (2013): La política en armas y las armas de la política. Brasil, Chile y Uruguay. 1950-1970. Buenos Aires, CLACSO.

Power, M. (2008): La mujer de derecha. El poder femenino y la lucha contra Salvador Allende, 1964-1973. Santiago, DIBAM.

Pinto, J. (2005): Cuando hicimos historia. La experiencia de la Unidad Popular. Santiago, LOM.

Riquelme, A. (2007): "Los modelos revolucionarios y el naufragio de la vía chilena al socialismo", Nuevo Mundo - Mundos Nuevos, 7.

Riquelme, A. (2008): "El alcance global de la Vía Chilena al Socialismo de Salvador Allende", en VV.AA., Salvador Allende. Fragmentos para una historia. Santiago, Fundación Salvador Allende, pp. 117-139.

Rojas, J. (2000): "Los trabajadores en la historiografía chilena: balance y proyecciones”, Revista de Economía \& Trabajo/PET, 10.

Rojas, J. (2004): Los trabajadores chilenos, desde la colonia hasta 1973. Santiago, CEME.

Rolle, C. (2003): 1973: La vida cotidiana de un año crucial. Santiago, Planeta. 
Rosemblatt, K. (1995): "Por un hogar bien constituido. El Estado y su política familiar en los Frentes Populares", en L. Godoy, ed., Disciplina y desacato. Construcción de identidad en Chile, siglos XIX y XX. Santiago, SUR, pp. 181-222.

Scully, T. (1992): Los partidos de centro y la evolución política chilena. Santiago, CIEPLAN.

Stillerman, J. (2005): "Comunidades, rupturas y coyunturas de los obreros de MADECO S. A., 1973-2003”, Política, 44, pp. 165-196.

Thielemann, L. (2018): "La rudeza pagana: sobre la radicalización del movimiento obrero en los largos sesenta. Chile, 1957-1970”, Izquierdas, 44, pp. 114-133.

Thompson, E. P. (2012): La formación de la clase obrera en Inglaterra. Madrid, Capitán Swing.

Tinsman, H. (1995): "Los patrones del hogar: esposas golpeadas y control sexual en Chile rural, 1958-1988”, en L. Godoy, ed. Disciplina y desacato. Construcción de identidad en Chile, siglos XIX y XX. Santiago, SUR, pp. 111-146.

Tinsman, H. (2009): La tierra para el que la trabaja. Género, sexualidad y movimientos campesinos en la Reforma Agraria chilena. Santiago, LOM.

Viotti da Costa, E. (1989): "Experience versus Structures: New Tendencies in the History of Labor and the Working Class in Latin America: What Do We Gain? What Do We Lose?, International Labor and Working-Class History, 36.

Weinstein, B. (1989): "The New Latin American Labor History: What We Gain", International Labor and Working-Class History, 6.

Williams, R. (2000): Marxismo y literatura. Barcelona, Península.

Winn, P. (2004): Tejedores de la revolución. Los trabajadores de Yarur y la vía chilena al socialismo. Santiago, LOM.

Zarate, M. y L. Godoy (2005): “Análisis crítico de los estudios históricos del trabajo femenino", Cuadernos de Investigación № 2. Santiago, CEM. 
Zavala, X. (2005): Memorias de ocupación. Violencia sexual contra mujeres detenidas durante la dictadura. Santiago, Andros.

Fecha de recepción: 2 de septiembre de 2020

Fecha de aceptación: 11 de noviembre de 2020 